\title{
USE OF MEASURED FORCE AS AN INDICATOR FOR END FACE CONTACT IN MECHANICAL FIBER OPTIC SPLICING
}

\author{
Nicholas Peterson, ${ }^{\mathbf{1}}$ Bradley Yost, ${ }^{\mathbf{1}}$ Elizabeth Meiser, ${ }^{\mathbf{1}}$ Eric Heard, ${ }^{\mathbf{1}}$ William Boyden, ${ }^{\mathbf{1}}$ \\ Michael Block, ${ }^{1}$ David Gafaglione, ${ }^{1}$ Juock Namkung, ${ }^{1}$ Joseph Tsang ${ }^{2}$ and Mark Beranek ${ }^{1}$ \\ Naval Air Systems Command \\ ${ }^{1}$ Patuxent River, Maryland \\ ${ }^{2}$ China Lake, California \\ Jeffrey R. DiMaio, Adam Haldeman, Joseph Murray, Kelum Randunu, \\ Margaret Shaughnessy and Quynh-ho Taylor \\ Tetramer Technologies \\ Pendleton, South Carolina
}

\section{Introduction}

Mechanical fiber optic splicing using ultraviolet light (UV) curable adhesive to bond and index match optical fibers is well established [1-2]. However; the current methods rely upon the operator to insert prepared optical fibers into the splice and determine the correct insertion distances manually. This paper describes the use of a computer controlled apparatus to insert the optical fibers as well as measure mechanical forces to indicate the correct end face contact. The aim of this effort is to develop a splicing method that can consistently produce low insertion loss mechanical splices. In addition to this method, this effort utilizes a new refractive index matching material developed by Tetramer Technologies. This material was designed to meet the requirements of MIL-PRF-24623/7 and MIL-PRF-28800F, while maintaining a shelf life of 6 months or longer without refrigeration, which is beyond the performance of state-of-the art commercial UV-curable optical resins [3-4].

\section{Mechanical Splicing Apparatus}

An initial investigation was conducted to better understand the causes of high insertion loss in mechanical splices. It was determined that a major contributor to insertion loss was axial misalignment of the two fiber end faces. Even when using an index matching optical resin or gel, a gap of a single millimeter can introduce $10 \mathrm{~dB}$ of insertion loss to a splice. The goal of this project is to create a reliable and repeatable method to minimize this gap length and produce low insertion loss mechanical splices. Two methods were investigated; active optical imaging and mechanical force monitoring. This paper focuses on the latter method.

The test apparatus, as shown in Figure 1, consists of two symmetrical fixtures. Each fixture consists of a v-grooved force gauge mounted on linear motion stage. Between these motion fixtures, is a third stage used to hold the glass capillary. The motion stages are moved towards the capillary, while the axial forces on each fiber are measured. The motion stages are controlled via a computer running LabVIEW, which also collects the data from the force gauges and from any optical measurement equipment.

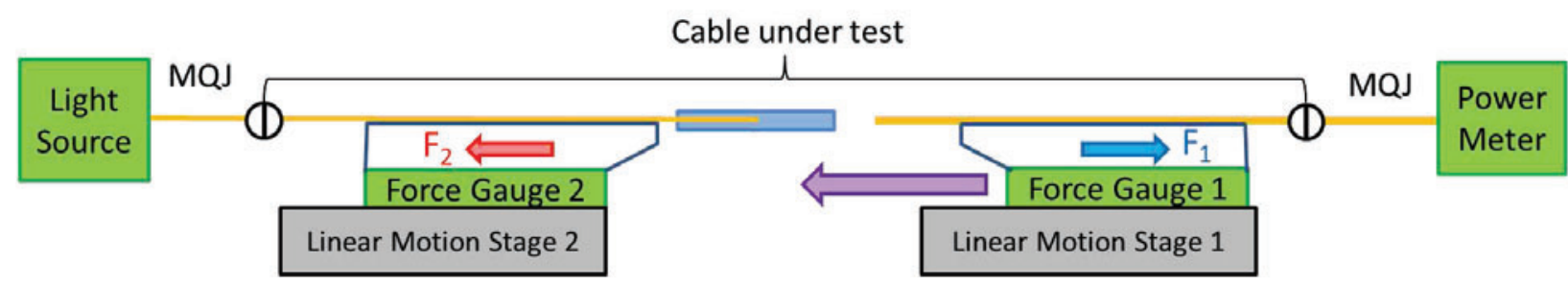

Figure 1: Mechanical Splicing Apparatus. The capillary is shown in the center in blue. 


\section{Optical Measurements}

The optical fiber used for this test was single-mode OFS Flightlink C24895. The capillaries were 16 $\mathrm{mm}$ borosilicate glass with $127 \mu \mathrm{m}$ square bores. The central wavelength of the laser source was 1550 $\mathrm{nm}$. The UV curable optical resin used in this study is based on photoinitiated free-radical chemistry.

The optical link shown in Figure 1 was constructed, with the source power set to $8.00 \mathrm{dBm}$ and the initial optical power was recorded at the power meter. The cable under test was cut in the center and both ends were stripped and placed within the v-grooved force gauges. The optical fibers were cleaved such that $2 \mathrm{~cm}$ of bare fiber extended from the force gauges. The optical fiber in fixture 2 was inserted into the resin filled capillary. At this point the measurement system was activated and the fiber in fixture 1 was inserted into the capillary at $0.25 \mathrm{~mm} / \mathrm{sec}$. The mechanical forces on each fiber (F1 and F2) as well as the insertion loss of the splice were recorded as shown in Figure 2.

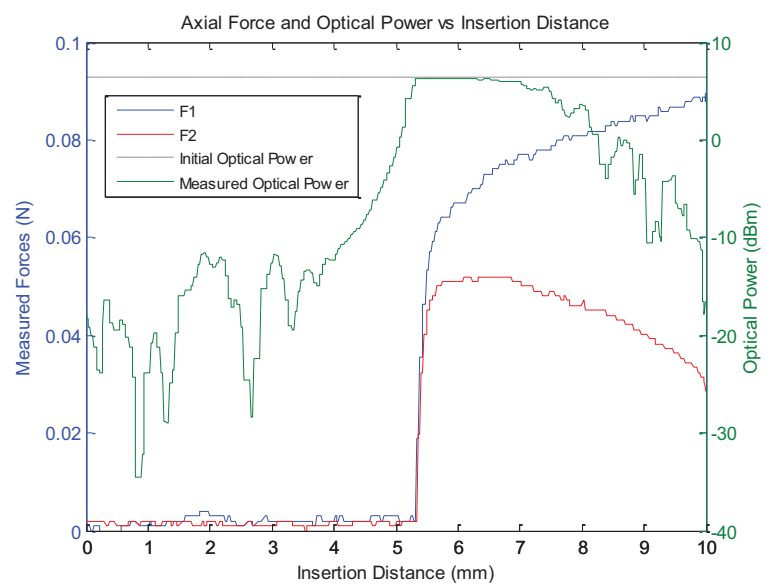

(a)

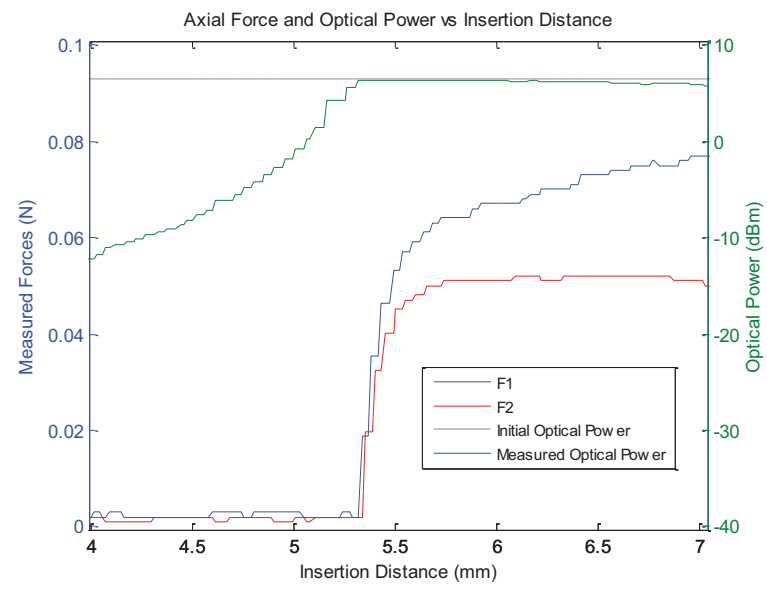

(b)

Figure 2: (a) Typical results from splicing apparatus. (b) Detail measurement in contact region.

\section{Results}

In all trials, both measured forces spiked sharply upon end face contact. The optical power throughput plateaued for an insertion distance of nearly $2 \mathrm{~mm}$ before decreasing due to fiber bending outside of the capillary. This plateau corresponded to insertion losses as low as $0.12 \mathrm{~dB}$, and was typically below 0.3 $\mathrm{dB}$. Our results show that these force spikes strongly coincided with the maxima in optical power; meaning that forces measured in this way can be used as an indicator during construction of low insertion loss mechanical fiber optic splices. Future work involves adapting our apparatus to automatically halt motion when the force spikes are detected, making similar measurements using multimode optical fibers, and miniaturization for transition towards fielding this unit as support equipment.

\section{References}

[1] K. Liu, C. Qian, C. and A. Kost, “Avionics fiber optic cable splice - RuggedConnect ${ }^{\mathrm{TM}}$, Proc. IEEE Avionics Fiber-Optics and Photonics Conference, San Diego, CA, October, 2008.

[2] V.D. Tran, M. Beranek, M. Hackert, B. McDermott, N. Peterson, G. Burnham, V. Wu, J. Zhao, A. Christopher, G. Ciolfi and J. Mazurowski, "Aerospace cable repair via field-portable fiber optic tip shaping and permanent mechanical splice technology,” Proc. IEEE Avionics Fiber-Optics and Photonics Conference, San Diego, CA, October, 2011.

[3] MIL-PRF-24623/7, SPLICE, MECHANICAL, SIMPLEX FIBER OPTIC CABLE, AIRCRAFT, Defense Logistics Agency, Defense Supply Center, Columbus, Ohio.

[4] MIL-PRF-28800F, PERFORMANCE SPECIFICATION: TEST EQUIPMENT FOR USE WITH ELECTRICAL AND ELECTRONIC EQUIPMENT, GENERAL SPECIFICATION FOR. 